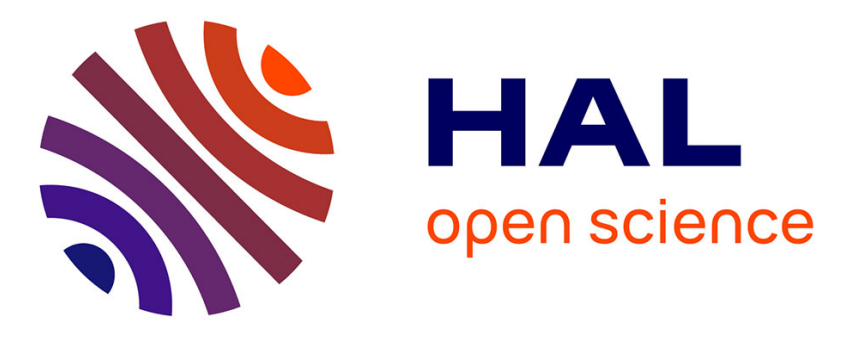

\title{
How adolescents with dyslexia dysorthographia use texting
}

Aurélie Simoës-Perlant, Marie-Pierre Thibault, Tonia Lanchantin, Céline

Combes, Olga Volckaert-Legrier, Pierre Largy

\section{To cite this version:}

Aurélie Simoës-Perlant, Marie-Pierre Thibault, Tonia Lanchantin, Céline Combes, Olga VolckaertLegrier, et al.. How adolescents with dyslexia dysorthographia use texting. Written Language and Literacy, 2012, 15 (1), pp.65-79. 10.1075/wll.15.1.04sim • hal-00762177

\section{HAL Id: hal-00762177 \\ https://hal.science/hal-00762177}

Submitted on 14 Oct 2017

HAL is a multi-disciplinary open access archive for the deposit and dissemination of scientific research documents, whether they are published or not. The documents may come from teaching and research institutions in France or abroad, or from public or private research centers.
L'archive ouverte pluridisciplinaire HAL, est destinée au dépôt et à la diffusion de documents scientifiques de niveau recherche, publiés ou non, émanant des établissements d'enseignement et de recherche français ou étrangers, des laboratoires publics ou privés. 


\section{John Benjamins Publishing Company}

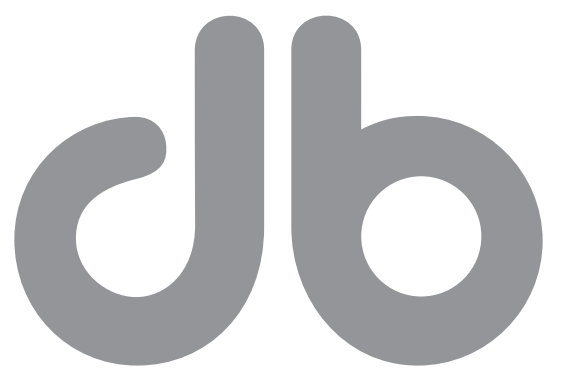

This is a contribution from Written Language \& Literacy 15:1

(C) 2012. John Benjamins Publishing Company

This electronic file may not be altered in any way.

The author(s) of this article is/are permitted to use this PDF file to generate printed copies to be used by way of offprints, for their personal use only.

Permission is granted by the publishers to post this file on a closed server which is accessible to members (students and staff) only of the author's/s' institute, it is not permitted to post this PDF on the open internet.

For any other use of this material prior written permission should be obtained from the publishers or through the Copyright Clearance Center (for USA: www.copyright.com). Please contact rights@benjamins.nl or consult our website: www.benjamins.com Tables of Contents, abstracts and guidelines are available at www.benjamins.com 


\title{
How adolescents with dyslexia dysorthographia use texting
}

\author{
Aurélie Simoës-Perlant, Marie-Pierre Thibault, \\ Tonia Lanchantin, Céline Combes, Olga Volckaert-Legrier \& \\ Pierre Largy \\ University of Toulouse 2 - Le Mirail, France
}

\begin{abstract}
Adolescents with dyslexia dysorthographia have some phonological skill deficiency and/or visual-attention deficit. Knowing that these same skills are required to use SMS codes, the main objective of this study is to understand how these subjects use texting language. To understand this, we compared the SMSs of adolescents with dyslexia dysorthographia with the SMSs of typical writers in a dictation task. We analyzed the number and the type of SMS codes used by the subjects. This study shows less use of SMS codes in quantitative terms in adolescents with dyslexia dysorthographia (DD), but globally equivalent use in terms of quality, in comparison with normal writers.
\end{abstract}

Keywords: adolescent; SMS language; dyslexia; dysorthographia; writing; development

\section{Introduction}

The mobile phone is one of the most widely used means of communication today. According to recent surveys, over $79 \%$ of French people have a mobile phone for personal and/or professional use; with this figure reaching nearly 95\% for young people aged 15 to 25 (TNS Sofres 2009). The Short Message Service (SMS), which allows users to send short text messages via mobile phone, is extremely popular. Indeed, 77\% of the French population over the age of 12 reports using mobile phones to send text messages every day. Nevertheless, SMS messages popularity is less pronounced in France than it is in other European countries, where the use of SMS approaches $90 \%$. In the USA, American people send 740 billion SMSs for the first half-year 2009, that is about 4.1 billion per day (CTIA 2009). 
Due to the tremendous SMS increase in use since its inception in 1992, this kind of communication became the centre of interest of much research. One of the most important problems significantly affecting the field was the new sort of language prompted by SMS. The space constraints related to SMS (the number of characters per message is limited to 160) coupled with its instantaneous nature have created a new kind of spelling based on several criteria.

Texting language has quickly become associated with the principle of shortening words and phrases through the use of abbreviations and phonological processes (e.g. à demain 'ok see you tomorrow' becomes a $2 \mathrm{~m} 1$ ). Dejond \& Mercier (2002) speak of a language written in its form but spoken in its content, in the meaning that it combines both written and spoken languages. Lienard (2005) described this phenomenon as a mixture of oral and written (e.g. Qu'est-ce que tu fais? 'What are you doing?' is pronounced Kesktufé, which does not preclude understanding).

SMS messages differentiate from conventional spelling mainly because of the traditional freedom and flexibility of use they offer to writers. "Language is not static; it is permeable to every novelty, creation and innovation; users like to be surprised and the key word is the game" (Dejond 2006: 10). The same writer can use various SMS codes (changes made to words during texting) depending on who the recipient is and what his purposes are. Furthermore, the same character spread may have several meanings; the reader has to decipher and take into account the great variety of SMS written forms.

The alphabet operates on two principles: on the one hand, the phonographic principle based on the sound dimension of language, where the written units denote oral units; and on the other hand, the semiographic principle based on the morphographic dimension of language, where the written units denote units of meaning. These two principles coexist and complement each other but one may influence the other depending on the context (Jaffré 2006).

Based on this model, Tran, Trancard and Servant (2008) have identified two categories of SMS processes, corresponding to these two principles. On the one hand, the 'phonographic' processes in which the subject (a) removes certain letters of the grapheme (usually silent letters or double letters: salut 'hello' becomes salu), and (b) uses numbers or letters whose pronunciation replaces the conventional form (e.g. qu'il 'that he' becomes kil; j'ai 'I have' becomes $G$ ). On the other hand, the 'semiographic' process requires a visual representation of the word. In this case, the subject (a) dispenses with the typographic elements such as spaces, capital letters, or accents and (b) truncates the word (e.g. copain 'buddy' becomes cop). However, texting is complex and it is not unusual to see combined processes of both types. Bonin \& Delattre (2010) show the existence of bidirectional links between the two ways of dual-route models. The SMS writer could use the direct route and the 
indirect route simultaneously. For example, the SMS process of omitting a silent letter (e.g. Salut 'hello' becomes salu) requires phonological skills and also knowledge of how to spell words.

According to different studies, 5 to $15 \%$ of children have written language difficulties (INSERM 2007). In secondary school, this proportion is estimated to be $15 \%$. These difficulties cover several aspects and concern (a) decoding abilities and/or (b) comprehension of written language. But not all these poor readers have a specific learning disorder in written language.

Dyslexia, the learning disorder specific to written language, has been given several definitions. For the World Health Organization (Organisation Mondiale de la Santé 1994), this disorder shows itself by difficulties in learning to read despite conventional education, adequate intelligence, and sociocultural opportunity. There is a fairly general consensus for 'developmental dyslexia', which corresponds to a significant gap of at least 2 years between intellectual and reading levels and interferes with scholastic success and/or daily activities. Thus, intellectual inefficiency, sensory deficit (visual or auditory), psychological, psychiatric or neurological problems, or inadequate or irregular scholastic education cannot explain the problem in its full complexity. The prevalence varies across countries and languages (e.g. E. Miles 2000; T.R. Miles 2004; Paulesu et al. 2001). Specific learning difficulties in written language often come with spelling disabilities. Today, we acknowledge that reading and spelling difficulties are the result of a phonological deficiency. However, the phonological hypothesis cannot explain the diversity of the different patterns of disorders (Valdois 2008). We describe below several types of written language learning disorders, knowing there are dyslexics who do not belong to a specific clinical picture.

Several forms of developmental dyslexia have been identified by referring to the dual-route model. These patterns are characterised by difficulty in setting up lexical and/or analytic procedures in reading. As 'visual dyslexia' or 'deep dyslexia' has not been discussed by many studies, we talk today of 'phonological' (dysphonetic) dyslexia and 'surface' (dyseidetic) dyslexia. Dysphonetic dyslexia involves the inability to break words down into sound parts, which greatly interferes with the application of the grapheme-phoneme conversion code. This profile of dyslexia is characterised by difficulties in reading nonwords (e.g. galupin) (Campbell \& Butterworth 1985; Funnel \& Davison 1989; Hulme \& Snowling 1992; Snowling \& Hulme 1989; Temple 1997; Temple \& Marshall 1983; Valdois, Bosse, Ans, Carbonnel \& Zorman 2003). The children reading performances with dyseidetic dyslexia surface are characterised by selective impairment of reading irregular words (e.g. femme 'woman'), while phonological ability is relatively intact (Coltheart, Curtis, Atkins \& Haller 1993; Goulandris \& Snowling 1991; Hanley \& Gard 1995; Hanley, Hastie \& Kay 1992; 
Temple 1984; Valdois \& al. 2003). A third profile can also be distinguished: it is described as mixed dyslexia and involves both disabilities. Current thinking tends to favour this form of dyslexia because of the globally weak reading performance of both irregular words and non-words (Brunsdon, Hannan, Nickel \& Coltheart 2002; Valdois, Bosse \& Tainturier 2004). This kind of dyslexia is often associated with dysorthographia, covering the disabilities identified in the two clinical profiles described above. The subjects have difficulties in phonemic awareness and also have visual-attention processing disorders. Mixed dyslexia is frequent and severe given the interdependence of the two types of reading. Research for this kind of dyslexia is only scant despite its frequency in the dyslexic population. That is why this particular disease has been chosen for the present study.

Very few studies have been undertaken among subjects with written language disorder. According to Plester, Wood \& Joshi (2009), knowledge of SMS codes is linked to good orthographic performance. They examined the relationship between the use of texting language and the literacy level of children between 10 and 11 years of age. The results show that SMS users have an appropriate level of phonological awareness. We would therefore expect the literature to show results displaying the same lines of difficulty in the use of texting language in adolescents with dysorthographia. Indeed, we are expecting an SMS language for adolescents with DD to be different from the one normal writers would use. While normal writers will use a wide variety of SMS codes like (a) the phonetic SMS one (with this kind of reducing: koi for quoi 'what') or the phonological form of numbers (as the number 1 used in place of the indefinite article $u n$, that is, two terms which describe exactly the same phoneme in French $[\tilde{\varepsilon}]$ ), or (b) the semiographic SMS codes (as truncations like ordi for ordinateur 'computer'), the adolescents with DD, who traditionally struggle with phonology, should give the privilege to some kind of SMS code (probably semiographic). This was emphasised by Durkin, Conti-Ramsdent \& Walker (2011) who use text-producing tasks to demonstrate that adolescents with specific learning impairment send SMSs that are shorter and less rich in vocabulary than normal readers. On the other hand, Tran et al. (2008) showed that dyslexia was not a major obstacle to using SMS. They argue that dyslexic performance (type and number of SMS codes) is comparable to that of normal readers and that writing SMSs facilitates writing for subjects with specific learning impairment. The less restrictive and more simplistic nature of the texting language and the limited number of characters used in messages facilitate the command of the code written by subjects with specific learning impairment. This mode of communication creates an 'uninhibited' relationship with SMS language, as 
if grammatical and spelling rules would not matter on the screen of a mobile phone. This interesting study has some limitations in our view. In SMSs written by subjects with specific learning impairment, the specific difficulties related to their disorder are observed. These are phonological processing difficulties and visual processing difficulties related to a poor orthographic lexicon. However, this study did not analyse the spelling performance of subjects upstream. Our aim was to understand the nature of SMS codes produced by dyslexics in order to identify (a) their specific characteristics and (b) avoid erroneously associating them with an SMS code.

Finally, a very interesting study conducted recently by Veater, Plester and Wood (2011) showed that 10 to 13 year olds with dyslexia use as many SMS codes (transcriptions) as the control group. On the other hand, the authors noticed a difference as regards the SMS codes nature used. Indeed, adolescents with dyslexia use more non-phonetic SMS codes such as emoticons (e.g. :-)) or initials (e.g. LOL 'lots of laughs') than non pathological adolescents do. The latter result seems particularly interesting.

Adolescents with DD have some phonological skills deficiency and/or visualattention deficit. Knowing that these same skills are required to use SMS codes, the main objective of this study is to understand how these subjects use texting language. This research will therefore address the following questions: (a) Do adolescents with DD use as many SMS codes as normal writers? (b) Do adolescents with DD use the same type of SMS codes (phonographic vs. semiographic) as normal writers? It is impossible to say for an adolescent with DD whether the texting language reflects the SMS code or the characteristic error of the disorder. In order to clarify this idea, we gave these adolescents a literary dictation to compare their performances in both areas. The main errors of the disorder thus appeared exactly the same in both dictations (SMS and literary). Although it is usual to find a word with several spellings in the writing of a person with surface dyslexia (e.g. gentil; janti; jenti 'kind') (Zorman 2002), this comparison will allow us to distinguish the characteristic errors of the disorder and thus avoid attributing them to SMS code.

In view of the literature on SMS and disorders, we assume that adolescents with DD use fewer SMS codes than normal writers. Adolescents with dysorthographia have some phonological difficulties. Also, according to Plester et al. (2009) and Veater et al. (2011), it is assumed that the type of SMS codes will differ between the two groups. So, based on the classification chosen for the analysis of SMS codes (see Part 3.2.), we expect that adolescents with DD will use fewer phonographic codes but more semiographic codes in SMS dictation than normal writers. 


\section{Method}

\subsection{Subjects}

Thirty subjects participated in the experiment (13 girls and 17 boys). All were French native speakers. Twenty five normal writers were matched on the basis of their chronological age with 15 adolescents with DD (normal writers: 13.27 [1.33] vs. adolescents with DD: 13.26 [1.18]). The chronological age difference between the two groups of subjects was not significant $(\mathrm{F}<1$, ns). The protocol was based on voluntary participation and parents' agreement was required.

We recruited the subjects according to (a) their SMS habits (identified through a questionnaire) and (b) their word identification skills (Exalang 11/15, Lenfant, Thibault \& Helloin 2009; cf. Table 1). Adolescents with DD have persistent and specific control difficulties and reading mechanisms automation. The difficulties correspond to a mixed clinical profile. None of the participants in this group had any sensory, intellectual, or psycho-emotional disorder. Their level of comprehension and memory was normal. It had been measured by BLI testing (Khomsi \& Khomsi 2002) or by L2MA (Chevrie-Muller, Simon \& Fournier 1997), depending on the subject's age. They evolved in an ordinary social-economic environment and attended school regularly. The reading level difference between the two groups was significant, $\mathrm{F}(1,28)=21.39, \mathrm{p}<0.001$.

Table 1. Subject characteristics

\begin{tabular}{llcc}
\hline Test & & Adolescents with DD & Normal writers \\
\hline Exalang & & & \\
& & -3.08 & 0.28 \\
& Time $^{*}$ & -5.36 & -0.44 \\
& Words read $^{*}$ & -4.05 & -0.33 \\
& Non-words read & \\
& Score $^{*}$ & -3.35 & 0.16 \\
\hline
\end{tabular}

*Significant at the 0.01 level

\subsection{Material and procedure}

\subsubsection{Control tasks}

Questionnaire

Initially, adolescents responded collectively to the questionnaire to define their SMS habits. The questionnaire was divided into three parts. The first part was mainly a series of personal information questions (e.g. name, age, grade, etc.). 
The second part asked which type of phone the subjects typically used. This information allowed us to determine which type of phone we may use in the experiment. The third part concerned their SMS habits (e.g. frequency, use of the dictionary, understanding, etc.). They were asked to answer the questions as honestly as possible. Each question was read aloud by the person conducting the experiment to ensure correct understanding.

Series of words

In order to control the expertise of the subjects in texting, we created series of proposals with words frequently used in the SMS language (e.g. quoi de neuf? 'what's new?', un ordinateur 'a computer', énervé 'angry'). These proposals are often used in SMS language. The subjects were asked to write the words by texting on the phone, which was on loan (they were not allowed to take the loaned phone home). The phone was identical for all subjects and was chosen to be more easily used by adolescents with $\mathrm{DD}$, following the results of the questionnaire. Besides allowing verification of subjects' expertise in texting language, this test also enabled them to take command of the experimental material for the subsequent tests.

This phase allowed the experimenter to explain how to operate the mobile phones and where the text keys were located. The objective of this control task was to measure the adolescents' expertise in SMS codes; so the speed of writing was not taken into account. After the explanations, the experimenter dictated 10 words or sentences to each adolescent who had to write them one after the other as he or she usually writes on his or her own phone. For the normal writers, we considered each transformation to be an SMS code (e.g. tout acheter 'buy everything' becomes tou achter). For adolescents with dysorthographia, we made an acceptance judgment based on the normal writers' results.

\subsubsection{Experimental task}

Two types of texts were dictated to the subjects: a literary text consisting of 46 words and 54 syllables and an SMS text consisting of 47 words and 52 syllables. Both texts had the same meaning and 43 words in common. The SMS dictation register was more informal than the literary dictation one. We believe this way to talk prompts these adolescents to use the SMS code.

Both texts were read normally, as a traditional dictation would be. Every single phoneme was pronounced in each group so that participants were able to write all of them down in a conventional written way or in SMS characters. The SMS dictation, thus, was read as words commonly are and not as they are written on a phone screen (for instance, Salut was read [saly] in both conditions and never $s(t)$. 
Literary dictation

Salut. Comment vas-tu? Es-tu au courant qu'il y a une fête demain chez Hervé? Connais-tu l'adresse? J'y vais avec un copain. Si tu veux y aller, on peut passer te prendre. J'attends ta réponse avant trois heures. A plus.

'Hi. How are you? Did you know that there's a party tomorrow at Hervés? Do you know the address? I'm going with a mate. If you want to go, we can pick you up. I expect to hear from you by 3 o'clock. See you later'

SMS dictation

Salut. Comment ça va? T'es au courant qu'il y a une fête demain chez Hervé? C'est quoi l'adresse? J'y vais avec un copain. Si tu veux y aller, on peut passer te prendre. J'attends ta réponse avant trois heures. A plus.

Subjects had to write both texts (literary and SMS). The literary dictation was written on paper and the SMS dictation was written on the phone. The order of the dictations was changed from one subject to another. Each dictation was read a first time in its entirety by the same experimenter. It was then dictated. Finally, subjects were allowed to review their writing one last time.

\section{Results}

\subsection{Control tasks}

Questionnaire

In this study, $100 \%$ of the adolescents owned a mobile phone. The majority, $67 \%$, of the adolescents with DD used a 'qwerty'-type keyboard (in fact, 'azerty' in France) as against 33\% using the more usual alphanumeric keypad. The pattern was reversed for the normal writers ( $83 \%$ had an alphanumeric keypad as against $17 \%$ who used a 'qwerty' keyboard). This result was helpful for the choice of phone loaned during dictation tasks. We opted for a phone with similar features as the phones mainly used by the adolescents with DD.

An interesting point concerns the SMS function. $92 \%$ of the normal writers said they used it as a substitute for voice calls. This was the case for only $42 \%$ of the adolescents with DD. Because SMS has the properties of speed and convenience for normal writers, they chose this service to exchange information with their friends. This was less so for the adolescents with DD who seemed to prefer the phone function. The T9 (predictive text) dictionary was mainly used by the normal writers ( $42 \%$ as against $8 \%$ of adolescents with DD).

Finally, the questionnaire highlighted the non-restrictive and accessible nature of SMS since $83 \%$ of the adolescents with DD and $100 \%$ of the normal writers claimed to read and understand SMS written code without any difficulty. 
Series of words

The dictation helped highlight the fact that the adolescents had knowledge of texting language. Similarly, we observed no significant difference between the two groups of adolescents in the number of transformations ( $\mathrm{t}$ test $=-0.50, \mathrm{dl}=25$, $\mathrm{p}>0.05)$ (normal writers $=65 \%$ vs. adolescents with $\mathrm{DD}=59 \%)$.

\subsection{Experimental task}

We considered an SMS code to be acceptable for all participants when the subjects used one or more SMS codes which corresponded to texting language: abbreviations with the purpose of using the fewest possible characters to obtain a comprehensible message. We also considered an SMS code to be unacceptable when the abbreviations did not (a) make it possible to recognise the word; (b) reduce the number of characters. It is the incomprehensible characteristic of an SMS word which has been chosen here to identify errors, equivalent to literary dictation misspellings. In adolescents with DD, it is particularely unclear whether the transformations are SMS codes which correspond to texting language or typical errors (e.g. ji vais).

In an attempt to better understand the SMS codes used by all the subjects, we compared the two dictations (literary and SMS) in order to link errors, knowing that all participants wrote both types of dictation. We considered ji vais 'I'm going' as an SMS code if it was transcribed j'y vais (correct French spelling) in the literary dictation. Conversely, we considered $j i$ vais as an error when it was transcribed in the same way in the literary dictation. Errors were not included in this analysis.

After identification and removal of errors, we identified all SMS codes used by the adolescents and created a system of classification. This classification system is adapted from Tran et al. (2008) and Anis (2002). We have seen that, according to Tran et al. (2008), phonographic SMS codes refer to phonological processing (non-lexical route) and semiographic SMS codes refer to the visual processing of words (lexical route). However, according to recent studies (e.g. Bonin et al. 2010), there are connections between the two routes. In the case of texting, the phonographic SMS code 'use of phonological form of a number' (e.g. demain 'tomorrow' becomes $2 \mathrm{ml}$; comparable to English for you becoming $4 U$ ) requires phonological skills, although we do not exclude a possible role played by visual processing. We also added the different types of SMS codes based on the writings of our study subjects. Because the classification system adapted from Tran et al. (2008) was not sufficient to evaluate our corpus, we added kinds of SMS from Anis' typology (2002). This included the code 'P5': reduction with compaction (Anis 2002), which is a combination of reducing the number of characters ( $q u$ becomes $k$ ) 
and telescoping words together (kia for qu'il $y a$ ). This classification is shown in Table 2. We compared the mean proportions of use of SMS language depending on the SMS codes and type of processes to which they referred.

Table 2. Classification system of SMS codes

\begin{tabular}{|c|c|c|}
\hline SMS codes & Type & Explanation \\
\hline P1 & Phonographic & $\begin{array}{l}\text { Reducing the number of letters in the grapheme ( } q u \text { becomes } \\
k \text {; ain becomes in (two different graphemes for the same } \\
\text { phoneme }[\tilde{\varepsilon}] \text { in French) }\end{array}$ \\
\hline $\mathrm{P} 2$ & Phonographic & $\begin{array}{l}\text { Omission of double letters or silent letters (comment } \\
\text { becomes coment; Hervé becomes Ervé) }\end{array}$ \\
\hline P3 & Phonographic & $\begin{array}{l}\text { Using the phonological form of numbers ( } u n \text { becomes } 1 \text { ), } \\
\text { signs (plus becomes }+ \text { ), or the value of the letters spelled } \\
\text { (jai becomes } G \text { ) }\end{array}$ \\
\hline $\mathrm{P} 4$ & Phonographic & $\begin{array}{l}\text { Grapheme substitution respecting the phonetic value of } \\
\text { statement }(i \text { becomes } y)\end{array}$ \\
\hline P5 & Semiographic & Reduction with compaction (qu'il y a becomes kia) \\
\hline P6 & Semiographic & Replacing a word with its homophone (c'est becomes ses) \\
\hline P7 & Semiographic & $\begin{array}{l}\text { Omission of characters: uppercase letters, spaces, accents } \\
\text { and punctuation (on } y \text { va becomes onyva, } a \text { becomes } a \text { ) }\end{array}$ \\
\hline P8 & Semiographic & $\begin{array}{l}\text { Truncation: (ordinateur becomes ordi; heure becomes } h \text { ) } \\
\text { and consonant skeleton (avec becomes avc) }\end{array}$ \\
\hline P9 & Semiographic & $\begin{array}{l}\text { Replacing a word by a word with the same meaning or an } \\
\text { Anglicism (copain becomes pote; aller becomes go) }\end{array}$ \\
\hline
\end{tabular}

These data were introduced to 2 groups (adolescents with DD vs. normal writers) $\mathrm{x} 2$ types of processes (phonographics vs. semiographics), with mixed design ANOVAs.

Mauchly's tests were used to test the sphericity theory. If the sphericity theory was rejected, we used the Greenhouse-Geisser correction. Each result was reported with a partial Eta squared $\mathrm{n}_{\mathrm{p}}^{2}$ as effect size. If $\mathrm{n}_{\mathrm{p}}^{2}<.06$, the effect is small; if. $06<\mathrm{n}_{\mathrm{p}}^{2}<.14$, the effect is medium; if $\mathrm{n}_{\mathrm{p}}^{2}>.14$, the effect is high (Cohen 1988).

First, the dictation order did not cause significant difference, $F(1,268)=$ 2.68 , ns. The group effect was found to be significant: $F(1,266)=3.66, p=0.05$, $\mathrm{n}_{\mathrm{p}}^{2}=.02$. Normal writers used more SMS codes than adolescents with DD ( $48 \% \mathrm{vs}$. $39 \%)$. The type effect was also found to be significant: $F(1,266)=31.67, p<0.01$, $\mathrm{n}_{\mathrm{p}}^{2}=.14$. Overall, adolescents used more phonographic SMS codes than semiographic SMS codes (57\% vs. 30\%). On the other hand, Group x Type interaction was not significant: $F(1,266)=1.76$, ns. 
To refine these initial results, we conducted an SMS code analysis. The data were submitted to 2 groups (adolescents with DD vs. normal writers) x 9 SMS codes (P1-P9) with mixed design ANOVAs.

We again found a significant group effect: $F(1,252)=5.1, p<0.04, \mathrm{n}_{\mathrm{p}}^{2}=.02$. The SMS code effect was also significant: $F(8,252)=17.75, p<0.01, \mathrm{n}^{2}{ }_{\mathrm{p}}=.36$. Overall, a considerable difference in the use of certain SMS codes was demonstrated and is illustrated in Figure 1. Finally, Group x SMS code interaction was found to be marginally significant: $F(8,252)=1.8, p=0.07, \mathrm{n}_{\mathrm{p}}^{2}=.05$.

Noticeably large differences in the use of certain SMS codes according to the group are visible. This led us to explore the differences between the groups for each SMS code. Analysis revealed a significant difference in the use of P1 SMS code (reducing the number of letters in the grapheme) between the two groups: $F(1,28)=5.12, p<0.04, \mathrm{n}_{\mathrm{p}}^{2}=.16$. Normal writers used this SMS code more than the adolescents with DD (96\% vs. 58\%). No other effect was significant (P2, $F<1$, ns; P3, $F(1,28)=2.38$, ns; P4, $F(1,28)=3.7$, ns; P5, $F<1$, ns; P6, $F(1,28)=1.3$, ns; P7, $F<1$, ns; P8, $F<1$, ns; P9, $F(1,28)=2.65$, ns).

\section{Discussion}

The aim of this study was to understand how adolescents with DD use texting language. We wanted to answer two questions: (a) Do adolescents with DD use as many SMS codes as normal writers? (b) Do adolescents with DD use the same SMS codes as normal writers?

Our results validated our first assumption that adolescents with DD use fewer SMS codes than normal writers. This finding confirms the work of Durkin et al. (2011) but goes against the findings of Tran et al. (2008). While normal writers had an average of $48 \%$ of SMS codes in a message, adolescents with DD had an average of $39 \%$.

This interesting result, fairly controversial in the literature, seems to be directly linked to one of the findings highlighted following the completion of our questionnaire. While all the adolescents said they understood SMS language without any difficulty, it appeared that $92 \%$ of the normal writers used SMS as a substitute for voice calls, whereas this was the case for only $42 \%$ of the adolescents with DD, even though texting is faster, cheaper, easier, and more convenient than a phone call (Coe \& Oakhill 2011). This result seems particularly interesting. Adolescents with DD use fewer SMS codes than normal writers, and this may be due to the fact that SMS writing requires more time and efforts from them compared to what normal writers usually have to do to text with others. Thus, whereas SMS language is well-known for its fast and simple characteristics, texting loses its quick and 
inexpensive nature for adolescents with $\mathrm{DD}$ because of the difficulties related to generally writing.

Our second prediction, that adolescents with DD use fewer phonographic SMS codes but more semiographic SMS codes than normal writers, was not confirmed. The overall analysis failed to reveal significant differences between our two groups of subjects. On the other hand, the analysis of SMS codes highlighted a single difference in the use of P1 SMS code. While for all other SMS codes in our classification we observed no significant differences between our two groups of adolescents, it appears that normal writers reduce the number of letters in the grapheme to a greater extent than adolescents with DD (96\% vs. 58\%). This is explained by the fact that adolescents with DD have difficulty playing with the sound of words. Using this SMS code requires the ability to transcribe a grapheme phonetically by reducing the number of characters (e.g. qui becomes $k i$ ). This operation is extremely complex for adolescents with DD as, in the case of $q u i$, it means segmenting a trigram into a digram $(q u+i)$. To perform this segmentation, we must (a) have grapheme-phoneme correspondence $(q u=/ \mathrm{k} /)$; (b) have correspondence between equivalent graphemes $(q u=k)$; (c) recover in working memory the $i$ which had been isolated; and finally (d) merge everything. This operation is very cost-intensive for an adolescent with written language disorders. This result is consistent with Veater et al. (2011) who observe a preference for non-phonetic text abbreviations in the dyslexic group. Thus, the fact that the SMSs written by the adolescents with DD did not differ in quality from the SMSs written by the normal writers seems to highlight that these adolescents use other strategies that do not follow the phonological code but rely more on instance retrieval (Gunnarsson \& Largy 2010; Largy, Cousin, Bryant \& Fayol 2007).

To conclude, the study conducted among adolescents with DD shows less use of SMS codes in quantitative terms but globally equivalent use in terms of quality in comparison with normal writers. Nonetheless, the task proposed is somewhat alien to the natural context for sending SMSs for the adolescents in the study. Since they were under no constraints of either time or cost, they could (potentially) have revised their work, which they would probably not have done in a natural context. This constitutes a methodological bias that should be controlled in any future study. Even though adolescents with DD seem to be less comfortable with texting language ( $17 \%$ of them mention they do not always understand SMS), their writing is not so different from that of normal writers when they use it. Finally, using SMS as a mean of exchange and communication among adolescents is potentially less stigmatizing for adolescents with DD. We need to take an interest in this new kind of spelling. Further research on texting language and on the use of the phone as a communication tool of choice will certainly reveal more 
about written language difficulties and the mechanisms implemented by these adolescents.

\section{References}

Anis, Jacques (2002). Communication électronique scripturale et formes langagières. Paper presented at the Quatrièmes Rencontres Réseaux Humains/Réseaux Technologiques. Poitiers: RHRT.

Bonin, Patrick \& Marie Delattre (2010). La procédure de conversion phonie-graphie en production sous dictée. L'année psychologique 110:495-516.

Brunsdon, Ruth K., Timothy J. Hannan, Lyndsey Nickels \& Max Coltheart (2002). Successful treatment of sublexical reading deficits in a child with dyslexia of the mixed type. Neuropsychological rehabilitation 12: 199-229.

Campbell, Ruth \& Brian Butterworth (1985). Phonological dyslexia and dysgraphia in a highly literate subject: A developmental case with associated deficits of phonemic processing and awareness. The Quarterly Journal of Experimental Psychology Section A: Human Experimental Psychology 37:435-475.

Chevrie-Muller, Claude, Anne-Marie Simon \& Sylvie Fournier (1997). L2MA: Batterie pour l'examen psycholinguistique de l'enfant. Paris: ECPA.

Coe, J.E.L. \& Jane V. Oakhill (2011). 'txtN is ez $\mathrm{fu}$ no h2 $\mathrm{rd}$ ': The relation between reading ability and text-messaging behaviour. Journal of Computer Assisted Learning 27:4-17.

Cohen, Jacob (1988). Statistical power analysis for the behavioural sciences. Hillsdale, NJ: Lawrence Erlbaum.

Coltheart, Max, Brent Curtis, Paul Atkins \& Michael Haller (1993). Models of reading aloud: Dual-route and parallel-distributed-processing approaches. Psychological Review 100:589-608.

Dejond, Aurélie (2006). Cyber-langage. Bruxelles: Racine.

Dejond, Aurélia \& Jacques Mercier (2002). La cyberl@ngue française. Bruxelles: Renaissance du Livre.

Durkin, Kevin, Gina Conti-Ramsdent \& Allan J. Walker (2011). Txt lang: Texting, textism use and literacy abilities in adolescents with and without specific language impairment. Journal of Computer Assisted Learning 27:49-57.

Funnel, Elaine \& Margaret Davison (1989). Lexical capture: a developmental disorder of reading and spelling. Quaterly Journal of Experimental Psychology 41: 471-487.

Goulandris, Nata K. \& Maggie Snowling (1991). Visual memory deficits: A plausible cause of developmental dyslexia? Evidence from a single case study. Cognitive Neuropsychology 8: $127-154$.

Gunnarsson, Cecilia \& Pierre Largy (2010). Confrontation de données expérimentales à l'analyse d'un corpus: le cas de la récupération d'instances en production écrite. Synergies: Pays Scandinaves 5: 43-64.

Hanley, J. Richard \& Frances Gard (1995). A dissociation between developmental surface and phonological dyslexia in two undergraduate students. Neuropsychologia 33:909-914.

Hanley, J. Richard, Kim Hastie \& Janice Kay (1992). Developmental surface dyslexia and dysgraphia: An orthographic processing impairment. Quaterly Journal of Experimental Psychology 44:285-319. 
Hulme, Charles \& Margaret Snowling (1992). Deficits in output phonology: An explanation of reading failure? Cognitive Neuropsychology 3:47-72.

INSERM. (2007). Dyslexie, dysorthographie, dyscalculie: Bilan des données scientifiques. Paris: Les éditions Inserm.

Jaffré, Jean-Pierre (2006). Lorthographe du français est-elle une bonne orthographe ? In ONL (ed.), Enseigner la langue: Orthographe et grammaire, 13-38. Paris: ONL.

Khomsi, Abdelhamid \& J. Khomsi (2002). Bilan de lecture informatisé. Paris: ECPA.

Largy, Pierre, Marie-Paule Cousin, Peter Bryant \& Michel Fayol (2007). When memorized instances compete with rules: the case of number-noun agreement in written French. Journal of child Language 34:425-437.

Lenfant, Mickael, Marie-Pierre Thibault \& Marie-Christel Helloin (2009). EXALang 11-15: La batterie informatisée pour lexamen du langage oral, du langage écrit et des compétences transversales chez le collégien. Maromme: Orthomotus.

Liénard, Fabien (2005). SMS: une menace pour le français? Cerveau \& Psycho 12:28-31.

Miles, Elaine (2000). Dyslexia may show a different face in different languages. Dyslexia 6: 193-201.

Miles, Tim R. (2004). Some problems in determining the prevalence of dyslexia. Electronic Journal of Research in Educational Psychology 2:5-12.

Organisation Mondiale de la Santé (1994). Troubles spécifiques du développement des acquisitions scolaires. In Classification Internationale des Maladies. Chapitre V (F): Troubles mentaux et troubles du comportement. Critère de diagnostic pour la recherche, 132-135. Paris: Masson.

Paulesu, Eraldo, Jean-François Demonet, Ferruccio Fazio, Eamon McCrory, Valerie Chanoine, Nicola Brunswick, Stefano F. Cappa, Giuseppe Cossu, Michel Habib, C.D. Frith \& Uta Frith (2001). Dyslexia: Cultural diversity and biological unity. Science 291:2165-2167.

Plester, Beverly A., Clare Wood \& Puja Joshi (2009). Exploring the relationship between children's knowledge of text message abbreviations and school literacy outcomes. British Journal of Developmental Psychology 27: 145-162.

Snowling, Maggie J. \& Charles Hulme (1989). A longitudinal case study of developmental phonological dyslexia. Cognitive Neuropsychology 6:379-401.

Temple, Christine M. (1984). Surface dyslexia in a child with epilepsy. Neuropsychologia 22:569-576.

Temple, Christine M. (1997). Developmental cognitive neuropsychology. Hove: Psychology Press.

Temple, Christine M. \& John C. Marshall (1983). A case study of developmental phonological dyslexia. British Journal of Psychology 74:517-533.

TNS Sofres (2009). Les adolescents, leur téléphone portable et l'Internet mobile. Paris: TNS Sofres.

Tran, Thi Mai, Marine Trancart \& Domitille Servent (2008). Littéracie, SMS et troubles spécifiques du langage écrit. Paper presented at the Congrès mondial de Linguistique Française - CMLF’08, Paris.

Valdois, Sylviane (2008). Les processus en jeu dans le cadre des difficultés lexiques. Langage et pratique 41:60-68.

Valdois, Sylviane, Marie-Line Bosse, Bernard Ans, Serge Carbonnel \& Michel Zorman (2003). Phonological and visual processing deficits can dissociate in developmental dyslexia: evidence from two case studies. Reading and Writing 16:541-572.

Valdois, Sylviane, Marie-Line Bosse \& Marie-Jeanne Tainturier (2004). The cognitive deficits responsible for developmental dyslexia: Review of evidence for a selective visual attentional disorder. Dyslexia 10:1-24. 
Veater, Helen M., Beverly Plester \& Clare Wood (2011). Use of text message abbreviations and literacy skills in children with dyslexia. Dyslexia 17:65-71.

Zorman, Michel (2002). La dyslexie de surface développementale: Etude d'un cas. In Renée Cheminal \& Vincent Brun (eds.), Les dyslexies, 56-65. Paris: Masson.

\section{Corresponding author}

Aurélie Simoës-Perlant

UFR de Psychologie

Université de Toulouse II - Le Mirail

5 allées Antonio Machado

31058 Toulouse Cedex 9

France

simoes@univ-tlse2.fr 